\title{
Die Anfänge von Weihnachten und Epiphanias
}

\author{
Eine Anfrage an die Entstehungshypothesen
}

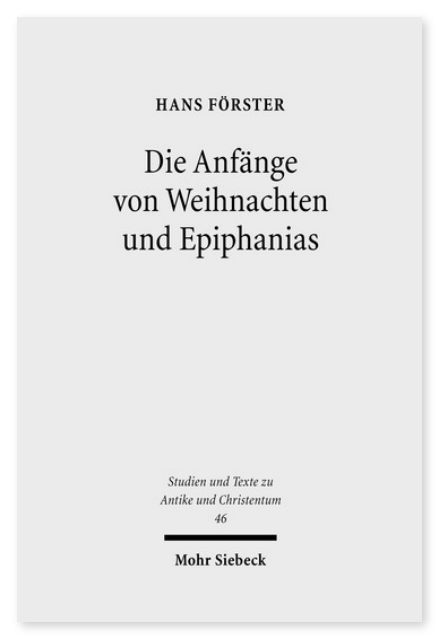

2007. XII, 342 Seiten. STAC 46

ISBN 978-3-16-151345-9

DOI 10.1628/978-3-16-151345-9

eBook PDF $109,00 €$

ISBN 978-3-16-149399-7

fadengeheftete Broschur 109,00€
Die wissenschaftliche Diskussion um die Entstehung von Weihnachten und Epiphanias kreist meist um zwei Entstehungshypothesen: Vor allem im angelsächsischen Sprachraum wird in der theologischen Literatur ein innerchristlicher Entstehungszusammenhang aufgrund von frühchristlichen Berechnungen favorisiert, während sonst meist auf parallele heidnische Feiern als Anlaß für die Entstehung der beiden Feste verwiesen wird. Eine derartige Parallelbildung eines christlichen Festes am Termin eines beliebten heidnischen Festes würde, so die weit verbreitete Ansicht, den heutigen Kenntnissen über die Inkulturation des Christentums entsprechen. Hans Förster zeigt, daß beide Hypothesen für die Entstehung von Weihnachten und Epiphanias die Situation des vierten Jahrhunderts nicht erklären können. Die Sonnensymbolik hat sicherlich zur Wahl des Festtermins entscheidend beigetragen. Sie konnte dies jedoch gerade deswegen, weil es eben kein paralleles römisches Sonnwendfest gab, das sich im vierten Jahrhundert besonderer Beliebtheit erfreut hätte. Das angeblich weit verbreitete und beliebte »Sol-Invictus-Fest « wurde vielmehr aufgrund einer höchst fragwürdigen Interpretation christlicher Quellen konstruiert; eine genaue Lektüre dieser Quellen vermag jedoch zu zeigen, daß es dieses Fest wahrscheinlich nicht gab, zumindest hat es sich um kein verbreitetes oder beliebtes Fest gehandelt. Dies bedeutet eine entscheidende Akzentverschiebung der gängigen Sicht des Christentums im vierten Jahrhundert.

Hans Förster Geboren 1969; 1997 Promotion; 1998-2003 Mitarbeit an verschiedenen Projekten des Österreichischen Wissenschaftsfonds (FWF) im Bereich Koptologie und Papyrologie; 2004-2006 APART-Stipendiat der Österreichischen Akademie der Wissenschaften; seit 2007 Mitarbeiter eines FWF-Projekts zur koptischen Papyrologie.

Jetzt bestellen:

https://mohrsiebeck.com/buch/die-anfaenge-von-weihnachten-und-epiphanias-9783161513459?no_cache=1 order@mohrsiebeck.com

Telefon: +49 (0)7071-923-17

Telefax: +49 (0)7071-51104 